\title{
The seven deadly sins of business development
}

\author{
Jeffrey J Stewart \& Ben Bonifant \\ Striking partnerships is a key ingredient to building a biotech company. In this article, we discuss seven common \\ mistakes that you should avoid during business development.
}

$B^{\mathrm{i}}$ iotech business development teams are tasked with finding a partner-usually a large pharmaceutical or biotech companythat will in-license intellectual property. To do this properly, the team members must understand their asset's potential value, attract partners, effectively communicate the asset's value to these partners and eventually close an out-licensing deal on mutually beneficial terms. The payments negotiated by the team are often critical to the financial health of the company as they may be needed to fund the ongoing development of key programs or to be the seed for investment in new programs.

During our years in the pharmaceutical and biotech sectors, we have worked with the business development teams of dozens of life science companies. Their practices ranged from excellent to questionable, and through our work we have seen the same pitfalls appear time and time again. Business development teams with poor habits run the risk of improperly estimating the potential value of their product assets, ineffectively communicating with potential partners and missing critical product- or market-related challenges. In the end, these teams face the prospect of failing to realize optimum value from the assets that the rest of the company has worked so hard to develop. Below, we summarize seven deadly-but all too common-sins of business development. Avoid these and your team will have a stronger chance of winning a deal (Table 1).

Jeffrey J. Stewart and Ben Bonifant are a consultant and vice president, respectively, in the business development practice at the specialized management consulting firm Campbell Alliance, Arco Corporate Drive, Suite 500, Raleigh, North Carolina 27617, USA.

e-mail:bbonifant@campbellalliance.com

\author{
Table 1 The seven deadly sins of business development (and how to avoid them) \\ $\operatorname{Sin} 1$ : telling the science story, not the market story \\ $\operatorname{Sin} 2$ : assuming the market is static \\ $\operatorname{Sin}$ 3: product blindness \\ $\operatorname{Sin} 4$ : failing to account for physicians' financial \\ motivations \\ Sin 5: ignoring reimbursement \\ $\operatorname{Sin} 6$ : speaking the wrong valuation language \\ Sin 7: pitching the 'perfect product' \\ Instead, realize the market is the story \\ Instead, project the future market \\ Instead, interview customers early \\ Instead, recognize physicians are human \\ Instead, know who pays for what and why \\ Instead, use the valuation method your audience \\ uses \\ Instead, be the party to disclose potential problems
}

\section{Sin 1: telling the science story, not the market story}

One common mistake is focusing on telling the 'story of the science'. In this case, the licensing story is presented as a journey of discovery-the audience is walked through every detail of early research, animal studies and initial development in a chronological sequence that mirrors the actual development process. In these presentations, the most compelling later-stage clinical information is withheld like a prize reserved only for those who are willing to experience the same ups and downs that the company's scientists endured. Moreover, the market need is buried below the science.

It's much more effective to tell the 'market story' by describing the market, identifying the unmet need and describing the science in the context of how the asset satisfies such a need. A top-notch business development team does this in the form of a target product profile-a multicomponent outline of product characteristics, each tested for consistency with the needs of the market. If the market need is compelling, investors will stay to learn how the science supports the ability of the product to hit the target product profile. The data must serve the main purpose: supporting the goal of out-licensing the asset (Fig. 1).
Sin 2: assuming the market is static Another ineffective practice is to think only about the competitors that exist today, when the relevant competitors are those of the future. A product may have a favorable profile relative to the other products currently on the market. For example, a drug approved for the treatment of chronic fatigue syndrome would be (as of this writing) the only approved product of its kind in the United States. It may be incorrect to assume that the competitive space will be just as pristine eight years down the road when your product is expected to reach the market. Potential partners may be keenly aware of where the market is heading, and ineffective foresight on your part can make both you and your team appear uninformed.

In contrast, make it clear that you know the details of competing products in advance and present these details to potential partners. Search the available listings of clinical trials in development (http://www.clinicaltrials. gov), understand how the entry of potential competitors might affect future revenue and share these findings with potential partners. One useful format is to present future competition in the form of scenario analyses, such as, "If product X is approved, then we believe the revenue picture may change in the following manner...". 


\section{Sin 3: product blindness}

All too often, business development teams understand the efficacy and safety of a product but not the effects that delivery methods and formulations may have on market acceptance. For example, a product may have a different market as an injectable than as a topical cream. Ignoring how delivery methods and formulations affect the market can cost you a negotiation.

In some cases, business development personnel mistakenly assume that a delivery method or formulation that is preferred in one setting is favored in all settings. For example, orally available small molecules are often preferred over infused drugs. However, applying that logic to certain oncology therapeutics could run counter to the practice of some oncologists, who sometimes prefer to administer infusional therapeutics because compliance is assured. There are also financial issues to take into account when weighing the merits of oral and infusional oncology products. (We describe this in more detail in regard to sins 4 and 5.)

The best route is considering the profiles of products on the market (and in development) and then asking which pharmaceutical would be chosen by physicians. Physician interviews can be essential to answering that question and to increasing a business development team's understanding of the marketplace. Interviews also provide potential partners with primary research data-often

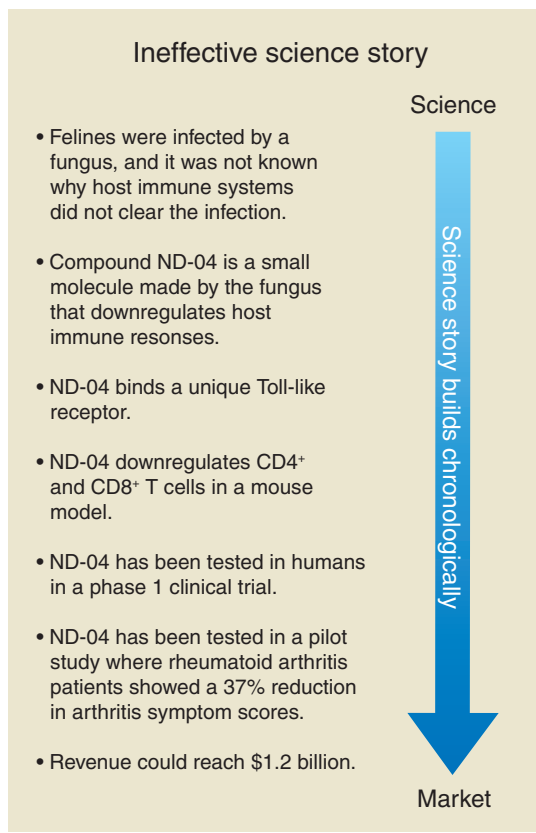

from both key opinion leaders and high-prescribing community practitioners. In later presentations, your team may be able to use such information to confirm or challenge claims raised by potential partners.

To cite an example from our own experience, we once interviewed physicians on the potential use of a medical device in an ambulance. Through these interviews, we learned that the procedure for which the new device was indicated did not actually need to be performed in the ambulance. This information effectively negated the assumed competitive advantage of the product and negatively affected its subsequent valuation. In another example, a label-free drug screening technology was initially conceived as a fee-for-service business because the company was unaware that pharmaceutical companies can be extremely resistant to sending any proprietary compounds beyond the company gates. In our experience, it can be enlightening to reach out early to future customers. Gathering their views will enable product planners to make key decisions from a position of market knowledge rather than market supposition.

\section{Sin 4: failing to account for physicians' financial motivations}

It is sometimes assumed that physicians are unaffected by financial considerations or that patient outcome trumps other considerations, even in the face of a negative

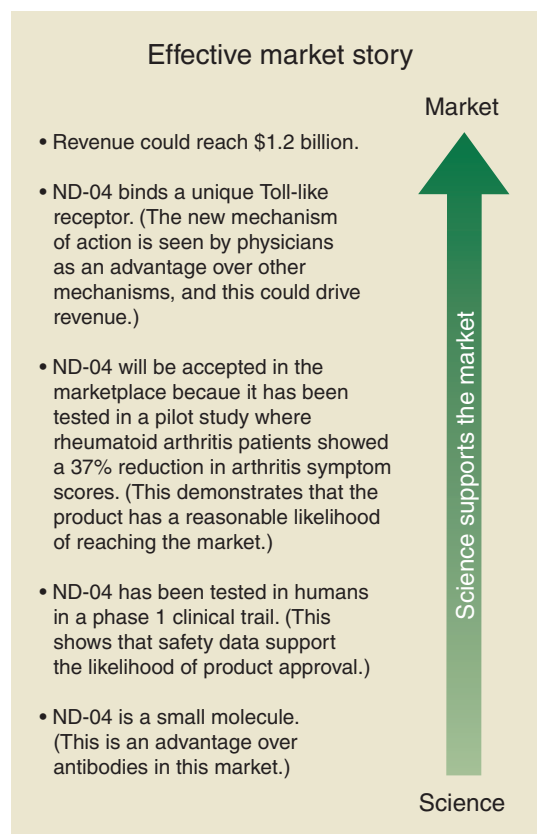

Figure 1 Two ways to tell compound ND-04's story. The story on the left might be a compelling technical talk for your colleagues, friends and family, but if you don't want go down in flames when pitching your product to potential business partners, we advise using the approach on the right. impact on physician profitability. Product forecasts made under this assumption do not account for the way that differing levels of reimbursement may affect physician behavior. These forecasts also overlook how the need to use existing infrastructure may affect therapy choice, and they ignore the degree to which physicians are disinclined to adopt products that place high demands on office operations.

In reality, the economic consequences for the prescribing physician have a very real effect on physician receptivity to a given therapy. For example, it has been argued that anti-CD20 radioimmunotherapies, such as Bexxar (tositumomab; ${ }^{131}$ I-anti-CD20) and Zevalin (ibritumomab; ${ }^{111}$ In-anti-CD20), failed to reach the anticipated market potential for treating non-Hodgkin's lymphoma in part because prescribing physicians lost profitability when referring patients to academic hospitals ${ }^{1}$.

It is important to be aware of physicians' financial motivations and either acknowledge the possible positive benefits of these motivations or discuss how they will be overcome. To give one example, an effective business development team would acknowledge that oncologists receive greater financial benefits from prescribing infusional therapeutics (administered in the office) than from oral medications (dispensed at pharmacies).

\section{Sin 5: ignoring reimbursement}

Your business development team should not assume that if customers demand a safe and effective new drug, they will receive it. That assumption discounts the payment source (for example, governmental bodies, insurers, patients), which is never a minor issue. Although the patient and his or her physician are often thought to be the only customers, and understanding their needs is believed to be the central factor in market acceptance, in reality insurers and governmental bodies play significant roles in treatment decisions.

To be effective, your team must recognize this and understand that the 'customer' is in large part the payer. Knowing who pays, and for what, is essential to understanding future market acceptance. A patient may desire a more convenient drug combination in a single pill, or a doctor may prefer convenience. However, a common quote among pharmacy directors is, "All other things being equal, we don't pay for convenience."

Returning to oncology therapeutics, oral therapeutics are reimbursed in the United States under Medicare Part D and may require a large patient co-payment. Infused therapeutics, on the other hand, are 


\section{Box 1 Valuation terms in common usage}

It pays to use the same valuation method used by your audience. Pharmaceutical companies primarily use net present value (NPV) and risk-adjusted NPV (rNPV); biotech companies and industry analysts mainly use rNPV; and venture capitalists often use comparable analysis ${ }^{2}$.

- NPV - the current value of predictable future cash flows. NPV $=x /(1+k)^{n}$. The net cash flow $(x)$ is discounted annually at the discount rate $(k)$ and is paid in $n$ years.

- rNPV-the current value of risky future cash flows. rNPV $=x r /(1+k)^{n}$. Net present value is risk adjusted ( $r$; typically clinical trial pass-or-fail probabilities).

- Real options-a valuation method based on financial options pricing in which options to increase or decrease investment are accounted.

- Peak revenue-the highest annual revenue a product achieves.

- Cash-on-cash valuation-a comparison of the cash invested in a company with the cash received upon liquidity. This is commonly used in private equity.

- Internal rate of return (IRR) - The 'interest rate' an investment earns.

- Comparable analysis-A potential investment's value at liquidity (exit value) is estimated by comparison to similar exit values. This is typically paired with IRR or cash-on-cash valuation.

- Monte Carlo simulation-Different outcomes are assigned probabilities and random numbers are used to generate a histogram of outcomes.

- Pre-money valuation - the value of a firm prior to investment.

- Post-money valuation - the value of a firm after investment (post-money valuation equals pre-money valuation plus the investment).

reimbursed under Medicare Part B and do not require high co-payments. Thus, reimbursement issues may lead to increased use of infused therapeutics even if patients would prefer oral administration. The goal for your team should be to estimate the reimbursement environment before a potential partner has the opportunity to deliver a rude awakening on that front.

\section{Sin 6: speaking the wrong valuation language}

Valuations are performed by the in-licenser or other investors and form a key basis of the investment decision. However, different investors use varying valuation methodologies. The worst thing a team can do is present value in the same way to every audience. You cannot view value as objective, and you cannot identify what you consider to be the best valuation methodology and then present it to every audience. For some audiences it would be a mistake to present high-, medium- and low-revenue estimates; the investment audience may only look at the lowest estimate and mentally chop it in half or more.

The best tack is to learn how each prospective investor performs valuations and either complete the valuation using that method or present the appropriate inputs so the investment team can rapidly make a valuation estimate. You must recognize that some companies use net present value (NPV) as a basis for valuation, whereas others prefer risk-adjusted net present value (rNPV); some use real options, and some use only peak revenue. When presenting to private investors, these teams may abandon NPV-type value estimation for a project and instead use cash-on-cash valuation with comparable analysis, which is commonly used in the private equity community (Box 1). For example, "Similar companies had initial public offerings at valuation $\mathrm{X}$, and we will reach this value in year three, for a cash-oncash return of $5 \mathrm{X}$ in three years." Also, determining the going 'pre-money value' - the value of the company before financing-for the private equity financing round is more important than presenting a well-reasoned argument for why the pre-money value should be significantly higher or lower than the going rate.

Speak the same valuation language as your customers.

\section{Sin 7: pitching the 'perfect product'}

All business development teams face the pressure of landing a partner. Ineffective teams allow this pressure to affect full disclosure about the product. A poorly trained team will pitch the 'perfect product'. But if a possible patent issue, safety concern or hidden cost is discovered late in due diligence, the potential partner may feel betrayed and abandon the partnership.
The grim reality is that due diligence teams are looking for holes in the product story. We have seen teams in the late stages of due diligence discover issues such as a challenging freedom-to-operate patent environment, resistance by targeted physicians to the selected paths of administration and positive phase 2 results that were concentrated in extreme changes in outcomes for a handful of patients. Once a due diligence team 'discovers' one of these issues, the entire process slows down, as concerns pop up about other surprises that might remain to be identified.

The truth is that no product is perfect, and your business development team should present potential disadvantages along with advantages. By being the party to address disadvantages, your team will maintain control of the issue and build credibility. At times, revealing product deficiencies early may lead to an early loss of a potential partner, but effective teams recognize that the partner would have been lost later in the process after a significant expenditure of effort.

\section{Conclusion}

By using the most effective methods in business development, teams will be able to present their product effectively to potential investors and partners, paving the way to success in the biotech market. Avoiding the seven deadly sins of business development will raise your company to a level of professionalism that pharmaceutical companies and investors expect from experienced partners. Telling the market story begins business development on the right foot. Speaking to the future market will start heads nodding. What potential customers say about a product will overshadow most other considerations. Considering physicians' financial motives will give partners comfort that you are realistic. Addressing reimbursement will allow partners to know they are not the only industry insiders in the room. Speaking your partner's valuation language means your partner has less translation to do and tells your partner that you both have similar outlooks on the world. And pitching your product 'warts and all' involves your audience in seeking solutions rather than in playing 'gotcha'. The seven deadly sins are just that-deadly. Avoiding them can bring your business development to life.

1. Berenson, A. Market forces cited in lymphoma drugs' dis use. The New York Times 14 July 2007, A1 <http://www. nytimes.com/2007/07/14/health/14lymphoma.html>.

2. Puran, S. The Valuation of Part-Developed Projects in the Pharmaceutical Sector. MS thesis, Cambridge Univ. (Cambridge Healthcare \& Biotech, Cambridge, UK, 2005). 